\title{
INICIOS LITERARIOS DE SALVADOR RUEDA EN MADRID (1882-1885)
}

\author{
SALVADOR RUEDA'S LITERARY BEGINNINGS \\ IN MADRID (1882-1885)
}

María Isabel JimÉnez Morales
Universidad de Málaga
jimor@uma.es

Fecha de recepción: 20-11-2018

Fecha de aceptación: 15-03-2019

\section{RESUMEN}

Este artículo aborda los primeros años de residencia en Madrid de Salvador Rueda, para lo cual ha sido de suma importancia el estudio de su correspondencia con Narciso Díaz de Escovar. Comprende desde 1882 — cuando empieza a trabajar como empleado público - hasta 1885, año en que ve la luz Poema nacional e ingresa en El Globo, diario donde publicará más de un centenar y medio de cuentos y artículos de costumbres en prosa. Este aspecto tan puntual de su biografía apenas ha sido estudiado por la crítica, que se ha limitado a repetir las mismas vaguedades e imprecisiones. Conocer mejor sus inicios literarios - publicaciones, colaboraciones en prensa, recitales...- ayudará a ofrecer un retrato más exacto y completo del escritor.

PAlabras Clave: Salvador Rueda, biografía, inicios literarios

\section{AbStract}

This article deals with Salvador Rueda's first years of residence in Madrid; for this purpose, the study of his letters to Narciso Díaz de Escovar has been essential. The article's scope is from 1882 — when Rueda started working as a public employee - to 1885 , when 
he printed Poema nacional and began his work as editor at El Globo, the newspaper where he will publish over 150 tales and articles "of manners". This very specific aspect of his biography has seldom been studied by the critics, most of whom have limited themselves to repeating the same vagueness and inaccuracies. Becoming familiar with Rueda's literary beginnings — books, press contributions, poetic recitals — will help to offer a more accurate and complete portrait of the writer.

KEY WORDS: Salvador Rueda, biography, literary beginnings

Investigando recientemente otros aspectos de la obra del escritor malagueño, he podido comprobar que, pese a existir magníficos estudios (CUEVAS, 1986), los primeros años de Salvador Rueda en Madrid han pasado desapercibidos para la crítica. No solo se han repetido las mismas vaguedades acerca de período biográfico tan puntual; sino que, además, se han sostenido muchas afirmaciones sin contrastar (RUIZ DE ALMODÓVAR, 1891; MARTÍNEZ OLMEDILLA, 1908; PRADOS Y LÓPEZ, 1941 y 1967; GIL MUÑIZ, 1957; VÁZQUEZ OTERO, 1960). Quizá influya que los investigadores han centrado mayoritariamente la atención en su poesía y en su importancia como renovador de la métrica modernista, sin olvidar la inevitable comparación entre el escritor malagueño y Rubén Darío. Las ideas imprecisas que se han reiterado sobre Salvador Rueda están relacionadas, principalmente, con su ingreso y colaboración en El Globo, con su dedicación exclusiva a la literatura tras su cese en La Gaceta de Madrid o con el hecho de que Núñez de Arce lo llamara a la corte siendo ya ministro. Pero no toda la culpa debe recaer sobre los estudiosos, el propio escritor solía contestar con generalidades cuando se le preguntaba sobre su primera etapa madrileña (El Caballero Audaz, 26-octubre-1918: 8). Conocer mejor sus inicios literarios ayudará a ofrecer un retrato más exacto y completo del escritor. Por ello, este artículo quiere profundizar en el arranque de su carrera, limitando el estudio hasta 1885, año en que Salvador Rueda comienza a disfrutar de cierto reconocimiento en la corte tras la publicación de Poema nacional y tras su ingreso en la redacción de El Globo, de suma trascendencia en su quehacer literario posterior.

El escritor malagueño se traslada a Madrid en plena Restauración. Su cambio de residencia tiene que ver con el deseo de triunfar en la corte, sabiendo que desde Málaga es casi imposible labrarse un porvenir en las letras. Algunos críticos coinciden en señalar 1882 como el año de su llegada a la corte (PAPPAS, 1970: 11; ESPEJO-SAAVEDRA, 1986: 13; CUEVAS, 1986: XXVII; NIEMEYER, 1992: 11; IsADO JiMÉNEZ, 1992: 10), hipótesis que confirman dos circunstancias muy concretas. La primera: nueve cartas que un joven Salvador Rueda escribe en Madrid y dirige a su amigo Narciso Díaz de Escovar desde febrero a diciembre de 1882 (QUILES FAZ, 1996: 36-60) y la segunda: su hoja de servicios como empleado público, conservada en el Archivo del Ministerio de Educación Nacional, en el que se puede comprobar que el 16 de enero de ese año ingresa como "aspirante oficial de Administración civil" en el ministerio de la Gobernación (TAMAYO, 1943: 31).

Ayuda a Salvador Rueda a conseguir sus sueños el poeta Gaspar Núñez de Arce, quien, con el tiempo, se convierte en su mentor y amigo. El propio Rueda, días antes de dar por concluida su etapa madrileña para instalarse definitivamente en Málaga, como empleado de la Biblioteca Provincial de la ciudad, recordaba así sus inicios de literato: "A los 
dieciséis años me llevaron mis padres a Málaga, donde comencé a escribir composiciones serias, que llegaron a oídos de Núñez de Arce, el cual me profetizó una vida célebre" (El Caballero Audaz, 26-octubre-1918: 8). El vínculo entre los dos escritores ya existía años antes. En agosto de 1880 un joven Salvador escribe un poema — "Arcanos. Canto"que dedica al escritor vallisoletano: "A mi querido maestro el eminente poeta don Gaspar Núñez de Arce, en testimonio de admiración y cariño" ${ }^{1}$. En respuesta, este remite a Rueda el 10 de septiembre una breve carta, de tono íntimo y cariñoso, donde le agradece en extremo la dedicatoria y reconoce que en él anima "el aliento de un verdadero poeta": "Usted tiene vuelos para aspirar a un puesto dignísimo en el Parnaso Español si medita y estudia". Le reprocha, no obstante, que, pese a sus pocos años, haya elegido el tema de la duda para "Arcanos", más acorde con poetas que han andado "largo trecho del camino de la vida": "La juventud debe fijar sus ojos en el sol que nace y no en la noche que vendrá; cantar los ideales de la vida, de la naturaleza, de la ciencia y de Dios, y no rendirse al cansancio cuando todavía no ha comenzado a marchar" (RUEDA, 1881: 10)².

Toda la crítica afirma que Gaspar Núñez de Arce llama a la capital al joven malagueño y que lo coloca en La Gaceta de Madrid. El propio Rueda afirmaría, incluso, que "con un destino de cinco mil reales" (El Caballero Audaz, 26-octubre-1918: 8). El escritor malagueño tiene entonces 24 años y desempeña tareas burocráticas en la oficina de La Gaceta. Así lo indica de forma muy breve en una carta fechada el 23 de febrero de 1882, aludiendo, indirectamente, al sosiego de su empleo: "Por lo demás me va bien: en la oficina no he tenido que tomar la pluma a la presente más que para escribir cartas a esa" (QUILES FAZ, 1996: 38). Varias de estas epístolas están escritas en papel con membrete de esa dirección y de la administración de la Imprenta Nacional. Rueda no solía mencionar las tareas que realizaba en sus diferentes destinos, por eso sorprende cuando hace una referencia — por breve que sea- a su labor en La Gaceta. Solo he encontrado tres alusiones a este primer empleo. La citada anteriormente y dos más donde se lamenta del horario de permanencia en la oficina, que le impide llevar a cabo encargos y gestiones que sus amigos le solicitan desde Málaga (QUILES FAZ, 1996: 57-58 y 60).

En lo referente a su ocupación en La Gaceta, un aspecto debe revisarse: la relación de este primer empleo de Rueda con el mandato de ministro de Ultramar de Gaspar Núñez de Arce. C. Cuevas (1986: XXVII) — siguiendo a Romo Arregui (1946: 55 y 240)— afirma que fue ministro en 1882 y que cesó en su cargo el 15 de febrero del siguiente año. En realidad, su mentor inicia la carrera ministerial el 9 de enero de 1883, cuando el malagueño ya

\footnotetext{
${ }^{1}$ El poema "Arcanos" reportó importantes beneficios literarios a Rueda. Tras su dedicatoria a Núñez de Arce el 27 de agosto de 1880, lo publica — junto a "Idilio"- en Dos poesías (1881). Asentado ya en Madrid, el 1 de agosto de 1882 "Arcanos" ve la luz en La Diana, revista dirigida por Manuel Reina, y lo incluye posteriormente en Noventa estrofas (1883a), obra que aparece también Con una carta de don Gaspar Núñez de Arce. Aquí elimina la fecha inicial de composición — 27 de agosto de 1880 - para no envejecer el poema. "Arcanos" es, asimismo, uno de los poemas elegidos por el malagueño para su lectura poética en el Ateneo de Madrid la noche del 26 de abril de 1884, acto que le consagra definitivamente en la corte como poeta colorista. La reseña del evento publicada en El Imparcial afirmaba que este poema era "algo difícil de descifrar" (ANÓNIMO, 27-abril-1884: 2).

2 Rueda publicó esta carta en Dos poesías, pero también vio la luz en la revista malagueña Andalucía el 19 de diciembre de 1880 (QUILES FAZ, 1996: 38).
} 
lleva al menos un año residiendo en Madrid (SÁNCHEZ ANDRÉS, 2003: 50) y, en consecuencia, meses después de ingresar en La Gaceta. Rueda deja este empleo más o menos al año, comunicando su traslado a Díaz de Escovar en una carta fechada el 5 de marzo de 1883: "te escribo enviándote las dos hojas restantes y anunciándote mi traslado al Ministerio de la Gobernación (Puerta del Sol) donde a tu disposición sigo" (QUILES FAZ, 1996: 61). Este cambio de destino se produce no porque sea cesado Núñez de Arce de su cargo lo que afirman todos los críticos-, sino probablemente por todo lo contrario: la mediación del flamante ministro favorece que Rueda sea destinado de La Gaceta a la Dirección General de Administración del Ministerio de la Gobernación, con la esperanza —que luego se vio frustrada - de un aumento de sueldo. Sus ilusiones primeras pronto se truncaron, pues en una epístola del 16 de marzo comentaba al mismo interlocutor: "debo darte la triste noticia de que no es con 6000 con lo que he sido trasladado a Gobernación, sino con el mismo sueldo que tenía. Espero sin embargo que pronto los tenga" (QUILES FAZ, 1996: 62) . $^{3}$ Esta es, a su vez, la única carta de las conservadas donde Rueda alude a Núñez de Arce como su "padrino ministro". Entonces el autor de El vértigo llevaba solo dos meses desempeñando el cargo y el malagueño lo menciona en relación a sus pretensiones de traer a su hermano José a Madrid con un buen empleo, para lo que, indudablemente, necesitaba la ayuda de su mentor ${ }^{4}$.

Instalado en Madrid, Salvador Rueda desempeña modestos destinos administrativos, que lo van trasladando a distintos despachos ministeriales ${ }^{5}$. Es, por tanto, equivocada la afirmación de quienes aseguran que, cesado en La Gaceta, se dedicó en exclusiva a la literatura (PRADOS Y LÓPEZ, 1941: 31; VÁZQUEZ OTERO, 1960: 53; ESPEJO-SAAVEDRA, 1986: 13). Es más acertado apuntar que su faceta de empleado público la simultanea con la literatura. Sus diversos trabajos no le impiden leer mucho, escribir, conocer a gente importante. Desea, por encima de cualquier cosa, consagrarse a las letras y, consciente de las dificultades que entraña, trabaja sin descanso. La falta de tiempo que dedicar a su for-

\footnotetext{
${ }^{3}$ Quiero recordar aquí que Núñez de Arce había prometido a Rueda en febrero de 1882, cuando trabajaba en La Gaceta, que "en breve haría por darme otro destino de mayor sueldo, o por que me aumenten el que hoy tengo" (QUILES FAZ, 1996: 38). Según su expediente administrativo (TAMAYO, 1943: 31-33), no aumentaría su sueldo a 1500 pesetas anuales hasta diciembre de 1886, cuando se traslada a Fomento, como temporero de la sección de Estadística. Mantendrá este salario en distintos destinos hasta agosto de 1889, cuando también en Fomento se convierte en "aspirante a la clase de primeros", con un sueldo de 2000 pesetas anuales.

${ }^{4}$ En una carta anterior, del 14 de septiembre de 1882, le escribe a su amigo malagueño: "Mi madre y mi hermano permanecen aún en Málaga, bien a pesar mío, no habiéndome sido posible buscar una colocación en Madrid al último, porque esto está más malo de lo que parece, en el sentido de colocaciones" (QUILES FAZ, 1996: 54). Transcurridos seis meses, seguía sin concretar sus planes: "Mi hermano desgraciadamente sigue en esa así como mi madre. Aún no he podido traérmelos, figúrate si tener un padrino ministro es alguna cosa extraordinaria" (QUILES FAZ, 1996: 62).

${ }^{5}$ Los membretes de las cartas que Salvador Rueda escribía a sus amigos son una buena fuente de información para reconstruir su trayectoria en la Administración del Estado. Es muy útil la reproducción de la hoja de servicios del poeta (TAMAYO, 1943: 31-33; PAPPAS, 1970: 32-34), pero, hasta el momento, la información más completa y exhaustiva de los puestos administrativos que desempeñó Salvador Rueda en Madrid puede encontrarse en la Cronología de Salvador Rueda (Salvador Rueda en el contexto de su época) (JIMÉNEZ MORALES-QUILES FAZ, 2013). Este apartado concreto ha sido elaborado por la Dra. Quiles Faz.
} 
mación es una queja constante en sus cartas 6 . Las editadas por A. Quiles Faz confirman su entrega completa a la literatura. En muchas de ellas se puede conocer mejor su relación con Núñez de Arce, entre amistosa y admirativa (CUEVAS, 1886: XXVII-XXVIII; QUILES FAZ, 1996: 36-50 y 2010: 149-150), pero también asuntos literarios de la más variada índole: presentación a certámenes, poesías que acaba de escribir, libros en proyecto, colaboraciones en periódicos y revistas, invitaciones de instituciones... Desde septiembre de 1882, y a lo largo del siguiente año, menudean las confidencias de Rueda sobre su prolífica actividad literaria. Comenta que está metido "en una porción de asuntos poéticos, de los cuales no puedo asegurar que saque adelante más que uno" o que tiene "mucho escrito que iré publicando paulatinamente" (QUILES FAZ, 1996: 59-60). Participa detalles tan nimios como que ha terminado un poema, que va a aparecer una poesía suya en tal o cual revista ${ }^{7}$, que está escribiendo una novela ${ }^{8}$ o — no con poco orgullo— que alguien "se dispone en esa [ $\mathrm{La}$ Diana] a hacer un trabajo sobre mis adelantos poéticos" (1996: 62).

Estos son algunos proyectos del joven malagueño, pero ¿cómo se materializan sus aspiraciones? Hasta el momento, solo había publicado dos obras en su ciudad natal (RUEDA, 1880 y 1881), tan decisiva la segunda en su relación con Núñez de Arce. Al instalarse en la capital, continúa su singladura literaria, aunque de forma modesta. El joven Rueda no vivía en 1880 en Madrid, pero de esta fecha son las primeras colaboraciones poéticas que he localizado en la prensa. De julio a diciembre publica sus versos en Día de Moda, revista

\footnotetext{
${ }^{6}$ Entresaco solo algunos ejemplos (todos en QUILES FAZ, 1996): en mayo de 1882 le dice a Díaz de Escovar que "todo el tiempo lo necesito ahora para el estudio" (p. 45). En septiembre del mismo año vuelve a comentarle que "todo el tiempo me viene escaso para estudiar y a nadie veo", o que no ha podido contestar a una de sus misivas "a causa de lo ocupado con los libros que he estado estos días" (p. 53). Y un poco más adelante, en la misma carta, le transmite sus esperanzas íntimas: "Creo que este amigo [se refiere a Plácido Langle] me perdonará pues bien sabe lo ocupado que estoy con los estudios literarios" (p. 54). Disfruta de tan escaso ocio que, tras felicitar a Díaz de Escovar por su triunfo en Pontevedra, le comunica, tajante: "Yo me dejé ya de certámenes". Al mes siguiente, el 17 de octubre de 1882, vuelve a escribirle y le anuncia que ya empieza en Madrid la temporada teatral, pero "desdichado de mí, [...] no podré ir este invierno ni a teatro ni a parte alguna. Todo el tiempo de que puedo disponer me viene escaso" (p. 58). En cambio, en otra carta, fechada el 9 de diciembre — la no 15 del epistolario-, le dice a su amigo Escovar que ha asistido a ocho estrenos que, por cierto, "han resultado otros tantos fracasos" (p. 59). Si tenemos en cuenta las dos fechas: entre el 17 de octubre y el 9 de diciembre de 1882 ha asistido al teatro más de una vez a la semana.

7 En la carta no 11 (26-junio-1882), le dice que ha terminado tres sonetos: "Química", "La elocuencia" y "Armonías", y que a su mentor le han gustado sobremanera. De hecho, subraya la opinión de Núñez de Arce, quien ha comentado que "manejo el soneto como pocos lo han manejado" (QUILES FAZ, 1996: 49). Al mismo tiempo, en la carta $\mathrm{n}^{\circ} 15$, del 9 de diciembre de 1882, le escribe, esperanzado: "Es posible que pronto publique mi Epístola de la cual creo haberte dado cuenta" (QUILES FAZ, 1996: 59). En la posdata de la no 18 (5-marzo-1883), anuncia que en uno de los próximos números de la Ilustración Española y Americana "saldrá regularmente una poesía mía que te va a gustar" y que en la última entrega de La Diana, ha publicado su oriental "El sultán". En la carta n ${ }^{\circ} 19$, del 16 de marzo de 1883, le dice que "La juerga" saldrá en La Diana en un número próximo (QUILES FAZ, 1996: 63).

${ }^{8}$ La carta $n^{\circ} 24$ (10-septiembre-1884) está plagada de información literaria. Es la primera vez que menciona la redacción de una novela: "que me propongo acabar este invierno, si el cólera lo permite" (QUILES FAZ, 1996: 69). Debe referirse a El gusano de luz, que no publica hasta 1889. Asimismo, comenta un sinfín de proyectos: "un largo canto al Arte", el primer canto "de un poema llamado Sixto", el primer cuadro de Castilla la Nueva, "que es La verbena de la Paloma" (p. 68). "Además tengo la mar de proyectos, que iré desenvolviendo a medida que pueda" (p. 69).
} 
dirigida por Eusebio Blasco9, y en noviembre aparece un soneto suyo en La Moda Elegante — "Grandeza de Dios. Soneto", (14-noviembre-1880)—. Al año siguiente amplía la nómina de revistas donde colabora a La América y El Correo de la Moda ${ }^{10}$. En 1882 continúa publicando poemas sueltos —especialmente sonetos- en La Diana, La América y La Ilustración Española y Americana ${ }^{11}$. A lo largo del siguiente año, inserta poesías en La Diana — "El sultán. Oriental" (1-marzo-1883)—, en La Moda Elegante — “Al mar. Oda" (22-abril-1883) - y en La Ilustración Española y Americana — "El brazo" (30-junio-1883), "A una mujer. Soneto" (30-septiembre-1883) y los sonetos "El cohete" y "Psicología y óptica" (30-octubre-1883) - . Hasta su ingreso en El Globo, efectuado en agosto de 1885, aumenta las publicaciones, aparte de las mencionadas ${ }^{12}$, a El Imparcial, La Iberia y La Época. Hay que advertir que, desde estos primeros años, ya apunta en él la costumbre de reutilizar el material poético. En ocasiones, incluye una misma poesía en diferentes cabeceras; otras veces, vemos que poemas de sus primeros libros los publica después en periódicos y revistas, o, el caso opuesto, los versos que ven la luz en la prensa madrileña los inserta en volúmenes posteriores, especialmente en Estrellas errantes. Asimismo, como consecuencia de este reciclaje literario, modifica el título de algunas de estas poesías ${ }^{13}$.

De forma simultánea a estas colaboraciones esporádicas en la prensa, entre mayo y junio de 1883, Rueda publica tres obras breves en forma de folletos (1883a, 1883b y 1883c), que han sido editadas recientemente por E. Garcés (RUEDA, 2016). Las tres ven la luz en Madrid, en el Establecimiento Tipo-Litográfico y podían adquirirse en las librerías de Mariano Murillo y Fernando Fe. Por la información ofrecida en la contraportada del primer folleto, Salvador Rueda tenía pensado dar a la luz un cuarto cuaderno: Sonetos, que, al menos, de forma independiente y con el título anunciado, no llegó a editar. Tal vez los sonetos que pretendía publicar en 1883 bajo título tan genérico, los incluyó años después en Estrellas errantes o terminaran formando parte de Himno a la carne, obra compuesta íntegramente por catorce de estas composiciones.

9 Vid. "El cohete. Soneto" (26-julio-1880), "Pensamiento" (27-septiembre-1880), "El entierro" (6-diciembre-1880) y "A ella. Soneto" (13-diciembre-1880).

${ }^{10}$ En la primera revista publica "La risa" (8-febrero-1881) y "El entierro" (8-septiembre-1881). En El Correo de la Moda aparece "En sueños. Soneto" (18-junio-1881).

${ }^{11}$ Publica en La Diana: "En sueños. Soneto" (16-junio-1882) y “Arcanos" (1-agosto-1882). En La América: "A una mujer. Soneto" (22-julio-1882); y en La Ilustración Española y Americana: "Armonías. Soneto" (30-septiembre-1882), "La elocuencia" (30-octubre-1882) y "La risa" (22-noviembre-1882).

12 En La Ilustración Española y Americana publica “Al Atlas. Soneto” (15-enero-1884), “¡Dios te salve! (A un niño)" (8-marzo-1885) y "La línea curva. Soneto" (30-agosto-1885) y en La Moda Elegante: "Dudas" (6-marzo-1885).

${ }^{13}$ De hecho, "La risa” y “A una mujer" los publicó en La América y en Ilustración Española y Americana. "El cohete", en Día de Moda e Ilustración Española y Americana; "El entierro", en La América y Día de Moda. "El sultán", "El entierro", "A una mujer", "Arcanos", "El cohete", "Grandeza de Dios" y "A una máscara" aparecieron antes en Renglones cortos y Dos poesías y, a posteriori, en la prensa madrileña. "La elocuencia", "Al Atlas", "Psicología y óptica", "El entierro", "A una mujer" y "El cohete" vieron la luz en los periódicos de la corte y, además, en Estrellas errantes. Con respecto a los cambios en los títulos, así ocurrió con "A una mujer", soneto publicado en varias revistas madrileñas, pero que en Renglones cortos llevaba el título de "Soneto. (Imitación de Rosas)". Igualmente, su poema "Al Atlas", mudó su título al de "A una altura”, cuando formó parte de Estrellas errantes. 
La prensa madrileña dio rendida cuenta de estas publicaciones, apareciendo numerosos anuncios en diferentes medios ${ }^{14}$. Era este un proyecto tras el que Rueda andaba desde el año anterior, tal y como se comprueba en su correspondencia. El 14 de septiembre de 1882 confiaba a Díaz de Escovar sus esperanzas más íntimas: "Este invierno creo que publicaré un libro con todo lo que he hecho. En otras te hablaré de él" (QUILES FAZ, 1996: 54). Para lamentar un mes después —el 17 de octubre-: "Un libro que pensaba publicar este invierno, ya no lo doy a luz por haber tirado de cuentas y encontrarme con que mis haberes están en merma. ¡Pícaro dinero!” (QUILES FAZ, 1996: 58). Entre marzo y abril de 1883, Rueda parecía alcanzar sus sueños, pues confesaba, jubiloso, a su amigo malagueño: "me ha salido un editor que desea dar a conocer en folletos todo lo que yo he escrito y lo que escriba en adelante. Ya veremos si cuaja la idea. En el momento en que se publique el primer cuaderno, que es donde va la poesía del metro nuevo, tendré mucho gusto en hacértelo conocer" (QUILES FAZ, 1996: 65). Ratificaba su proyecto en otra epístola: "lo de la publicación de mis cuadernos parece que se formaliza; pero ya sabes al paso que siempre marchan estas cosas", comentando un poco más adelante que ya había concluido Don Ramiro - el poema que estaba escribiendo cuando Díaz de Escovar, su interlocutor, viaja a Madrid y visita a Rueda-, que "constituirá el tercero de mis cuadernos próximos a publicarse" (QUILES FAZ, 1996: 66). Esta carta lleva la fecha del 14 de abril de 1883 y sus dos primeros cuadernos — Noventa estrofas y Cuadros de Andalucía - ven la luz a las pocas semanas.

Esos tres folletos contribuyeron, sin duda, a abrirle las puertas de diferentes instituciones madrileñas. La primera invitación de la que tengo constancia se formaliza el 24 de marzo de 1884, cuando interviene en una velada literaria en el Círculo Nacional de la Juventud, inaugurado en febrero de 1881. Una noticia de La Iberia, comentaba que ese día "se dio a conocer un poeta de brillantes cualidades [...] que llegará a obtener envidiable nombre apenas el público tenga ocasión de saborear sus versos"15. El crítico le auguraba un futuro halagüeño al tiempo que se sorprendía de su juventud. A su juicio, Rueda leyó poemas que le situaban "al lado de los discípulos de Núñez de Arce" y otros que recordaban "los mejores tiempos de Zorrilla". Las poesías más aplaudidas fueron "La orgía de esqueletos" - "cuadro fantástico preciosamente escrito"-; varios sonetos y los romances andaluces "Una juerga" y "A ver la novia". Según la crónica, el numeroso público aplaudió al malagueño con entusiasmo.

Al mes siguiente, concretamente el 26 de abril, Rueda consolida su triunfo en Madrid al leer sus poemas en el Ateneo. Gracias a su correspondencia, se deduce que la relación con esta institución se remonta al año anterior y que su intervención en ella se hizo esperar.

${ }^{14}$ Noventa estrofas se anunció en El Motín (6-mayo-1883, p. 3), La Diana (8-mayo-1883, p. 16), El Día (14 y 15-mayo-1883, p. 3), Madrid Cómico (20-mayo-1883, p. 7) —en esta ocasión junto a Cuadros de Andalucía - y La Raza Latina (15-julio-1883, p. 6). De Cuadros de Andalucía se hizo eco La Ilustración Española y Americana (30mayo-1883, p. 344) y El Día (11-junio-1883, p. 7). Y, conjuntamente con Don Ramiro, se publicitó en La Diana (8-junio-83, p. 14). Don Ramiro también se anunció en la sección "Bibliografía” de El Día (14-octubre-1883, p. 4). Información conjunta de las tres obras apareció en La Librería, n 10 a 12, julio-diciembre-1883, p. 164.

${ }^{15}$ La reseña del evento apareció en La Iberia, 26-marzo-1884, p. 2. El crítico reprodujo en su artículo el soneto titulado "La elocuencia". También se anunció el acto en La República, 22-marzo-1887, p. 3 y Rueda fue felicitado en una breve nota de El Liberal, 25-marzo-1884, p. 3. 
En una carta que escribe el 15 de febrero de 1883 le dice a su interlocutor que todavía no ha recitado en dicha institución porque "a consecuencia de haber leído en él el año pasado, entre otros, porción de poetas de cierta magnitud no muy voluminosa, ha resuelto la Sociedad que nadie absolutamente lea este año, para que no venga en descrédito el citado centro ateneísta" (QUILES FAZ, 1996: 60-61). Efectivamente, una noticia aparecida el 16 de octubre de 1882 en La Alianza, informaba que el Ateneo de Madrid llegó a plantear seriamente la supresión de lecturas poéticas, "porque la cátedra del ilustre centro se iba convirtiendo en escaparate de medianías". Fue tal "la sublevación de los poetas" que el Ateneo decidió dedicar "los domingos a la lectura" (SORIA ANDREU, 2002: 13). Cuando Salvador Rueda interviene el 26 de abril en el Ateneo, el acto resulta un completo éxito y representa para él un triunfo definitivo. No en balde, estas lecturas poéticas significaban para muchos escritores noveles y de provincias una forma de alcanzar un nombre en las letras. Los periódicos más importantes se hicieron eco del evento ${ }^{16}$, reseñándolo por extenso El Imparcial (ANÓNIMO, 27-abril-1884: 2). Varios de ellos resaltaron que la poesía "De ver la novia" tuvo que recitarla por segunda vez entre ruidosos aplausos. Rebosante de entusiasmo, Rueda escribe a su amigo Narciso Díaz unas semanas después (el 14 de mayo) y le comunica que el acto "ha sido todo lo brillante que yo podía desear habiendo estado unánime la prensa toda al juzgarme de manera tan benévola" (QUILES FAZ, 1996: 67). A su juicio, ha ganado "la batalla decisiva", pues "siempre me tienen invitado acá y allá, y siempre tengo que estar en algún salón recitando versos". Asumiendo forzosamente su popularidad, le confiesa en la misma carta que ha modificado su innata timidez: "Ya recito delante de la gente, y trato a mucha, y visto frac y hago cosas que ya sabes tú lo difíciles que eran para mí".

Rueda se da a conocer en Madrid publicando poesías, pero en agosto de 1884 inserta en Los Lunes de El Imparcial un cuadro de costumbres en prosa: "El copo y la moraga" (18-agosto-1884). Quizá sea este texto el aludido por el malagueño en una carta del 10 de septiembre del mismo año. En ella le dice a Díaz de Escovar que ha escrito "cuatro o cinco artículos que he vendido y publicado en algunos periódicos, entre ellos El Imparcial" (QUILES FAZ, 1996: 68-69). Esta referencia es una de las primeras a sus trabajos en prosa, pues casi todas las noticias literarias de su correspondencia se refieren a textos poéticos. De este modo, inaugura una nueva faceta que continúa en La Época (también con un único texto: "La caja de pasas. (Cuadro de costumbres malagueñas)", aparecido el 22 de diciembre de 1884) y, al año siguiente, en La Moda Elegante. En esta revista publica un mayor número de textos en prosa, todos en 1885: dos cuadros de costumbres - "La parranda" y "El columpio", aparecidos el 14 de marzo y el 14 de abril, respectivamente-, un cuento - "Virtud a prueba" (6-octubre-1885) - y una estampa lírica - "Un crepúsculo. (Esbozo)" (30-noviembre-1885)—. Estos artículos en prosa son los primeros de una larga lista de textos que publicará a partir de ese momento en las revistas y diarios en que colabora.

1885 fue un año relevante para Rueda. El joven escritor empieza a disfrutar de cierta popularidad en Madrid, la prensa lo juzga con benevolencia, frecuenta a importantes es-

16 Entre otros, vid. El Globo, 26-abril-1884, p. 3; El Liberal, 26-abril-1884, p. 3; La Correspondencia de España, 27-abril-1884, p. 3; Diario Oficial de Avisos de Madrid, 27-abril-1884, p. 3 y La República, 27-abril-1884, p. 3. 
critores y recita sus versos en reuniones y salones: "más vale estar de moda, que nadie se acuerde de uno", confesaba a su amigo (QUILES FAZ, 1996: 67). Sin contar su nombramiento de secretario segundo de la Sección de Bellas Artes del Ateneo de Madrid — producido el 13 de junio de ese año- ${ }^{17}$, los dos hechos más destacados en 1885 fueron la publicación de Poema nacional y su ingreso en la redacción de El Globo.

En efecto, a finales de abril, ve la luz una nueva obra del escritor: Poema nacional. I Costumbres populares ${ }^{18}$, que dedica al poeta José Velarde. Contemplada con el distanciamiento que dan los años y según su personal consideración, sería para el escritor su primer libro de verdad (El Caballero Audaz, 26-octubre-1918: 9). Se puso a la venta en la célebre librería de Fernando Fe y lo publicitó el 25 de abril en un nuevo recital celebrado en el Ateneo, donde leyó cinco de sus romances ${ }^{19}$. Costumbres populares era el primer título de un ambicioso proyecto: Poema nacional, formado por cinco tomos que se titularían, respectivamente: Costumbres populares, Figuras españolas, Cuadros del Norte, Batallas y Monumentos $^{20}$. Solo concluyó el primero de los volúmenes, aunque el segundo parecía tenerlo bastante avanzado, pues había elegido para incluir en su libro personalidades de la talla de Quevedo, Felipe II, Murillo, Pedro el Cruel, Zorrilla, Goya, Isabel la Católica...; y criaturas literarias como D. Quijote, D. Juan Tenorio, etc. Por el título y contenido de esta segunda entrega, el nuevo libro podría incluirse en esa poesía "premodernista" de exaltación de los valores positivos de la patria, donde se glorifica a sus hombres ejemplares (NIEMEYER, 1992: 148-155); que, en este caso especial, se hace extensible también a los personajes más universales de nuestra literatura. Poema nacional fue objeto de numerosos anuncios en la prensa entre abril y mayo de $1885^{21}$, siendo, en su conjunto, muy elogiosos.

En agosto de 1885, y no en 1883 como ha repetido buena parte de la crítica, ingresa como redactor literario en El Globo, ocupación que desempeñará hasta marzo de 1888, con colaboraciones muchas veces semanales. Su trabajo asiduo en este importante diario madrileño resultará de suma trascendencia en la evolución literaria de Salvador Rueda, inclinado hasta ese momento casi exclusivamente hacia la poesía. En sus páginas publicará más de un centenar y medio de artículos en prosa, que supusieron para el malagueño el paso de

17 Fue nombrado junto a José González de la Oliva, Miguel Aguirre y Augusto Moreno Nieto. Segismundo Moret presidía el Ateneo y la vicepresidencia recaía en su buen amigo Gaspar Núñez de Arce. Noticia aparecida en La Correspondencia de España, 14 y 15-junio-1885, pp. 3 y 2, respectivamente y en Diario Oficial de Avisos de Madrid, 15-junio-1885, p. 3. Vid. también AA. VV. (2016: 622).

18 Concretamente, apareció el 26 de abril de 1885. Dato localizado en un anuncio publicado en El Liberal: "se pondrá hoy a la venta" (26-abril-1885, p. 3).

19 Según El Imparcial (25-abril-1885, p. 2), los poemas recitados fueron: "La boda", "La guitarra", "La romería", "El ciego de los romances" y "La fiesta nacional". Además, aparecieron anuncios del libro en El Liberal, El Día, La Correspondencia de España y La Época, todos el 24 de abril de 1885.

20 Puede leerse esta información en la contracubierta del propio libro, pero diferentes medios glosaron también el proyecto. Entre otros: El Liberal, 26-abril-1885, p. 14; La Iberia, 26-abril-1885, p. 3 y Madrid Cómico, 24mayo-1885, p. 7.

${ }^{21}$ La reseña más extensa apareció en la sección "Libros nuevos" de La Época el 3 de julio de 1885, p. 4. Vid. también Orlando (1885: 295-296) y los anuncios de La Iberia, 26-abril-1885, p. 3; El Liberal, 26-abril-1885, p. 3; Revista de España, mayo-1885, p. 474; La Ilustración Española y Americana, 8-mayo-1885, p. 278 y Madrid Cómico, 24-mayo-1885, p. 7. 
la lírica a la narración breve, que luego desembocaría en el cultivo de la novela. Dos terceras partes de estos artículos surtirían las páginas de sus seis volúmenes de cuentos y cuadros de costumbres publicados entre 1886 y 1893 - El patio andaluz, El cielo alegre, Bajo la parra, Granada y Sevilla, Tanda de valses y Sinfonía callejera-y de su primera novela: El gusano de luz, de 1889. Los dos años y medio de trabajo en El Globo supusieron para el malagueño una importante etapa dentro de su producción literaria, centrada en el aprendizaje de la prosa poética y costumbrista, pero este aspecto rebasa los límites cronológicos propuestos en este artículo.

\section{REFERENCIAS BIBLIOGRÁFICAS}

AA.VV. (2016): Cargos históricos del Ateneo de Madrid. (1835-1936), Archivo del Ateneo.

Anónimo (27-abril-1884): "La velada del Ateneo", El Imparcial, p. 2.

Caballero Audaz, El (26-octubre-1918): "Nuestras visitas. Salvador Rueda", La Esfera, pp. 8-9.

Cuevas, Cristóbal (1986): "Ensayo introductorio", en Canciones y poemas. Antología concordada de su obra poética, Madrid, Fundación Ramón Areces, pp. XIX-CLI.

EsPejo-SaAvedra, RAfael (1986): Nuevo acercamiento a la poesía de Salvador Rueda, Sevilla, Servicio de Publicaciones de la Universidad de Sevilla.

Gil MuÑz, Antonio (1957): Salvador Rueda: su vida y su obra, s. 1., s. n.

Isado Jiménez, Pedro José (1992): Salvador Rueda, poeta modernista. (Recensión de tesis doctoral), Ciudad Real, Pedro J. Isado Jiménez.

Jiménez Morales, Ma Isabel y Quiles Faz, Amparo (Dirección digital), Portal "Salvador Rueda". Biblioteca Virtual Miguel de Cervantes, inaugurado el 17 de octubre de 2013. (http://www. cervantesvirtual.com/portales/salvador_rueda/)

Martínez Olmedilla, Augusto (1908): Salvador Rueda. Su significación, su vida, sus obras, Madrid, Gregorio Pueyo, Editor.

Niemeyer, Katharina (1992): La poesía del premodernismo español, Madrid, CSIC.

Orlando (1885): "Revista literaria. La lírica en este año [sobre Poema nacional. Costumbres populares]”, Revista de España, CVI, pp. 289-299.

Pappas, Theodore Luke (1970): Breve biografía de Salvador Rueda con sus cartas inéditas dirigidas a su primo, Charleston, The Citadel, The Military College of South Carolina.

Prados y López, Manuel (1941): Salvador Rueda, el poeta de la raza. (Su vida y su obra), Málaga, Imp. Zambrana.

- (1967): El poeta de la raza. Salvador Rueda renovador de la métrica. (Ensayo crítico-biográfico), Málaga, Diputación Provincial.

Quiles faZ, AMPARo (1996): Epistolario de Salvador Rueda. 1. Ciento treinta y una cartas autógrafas del poeta (1880-1932), Málaga, Arguval.

- (20I0): "Filias y fobias de un poeta modernista: Salvador Rueda", en Estudios sobre Salvador Rueda, Málaga, Sarriá, pp. 145-166.

Romo Arregui, Josefina (1946): Vida, poesía y estilo de D. Gaspar Núñez de Arce, Madrid, CSIC.

Rueda, Salvador (1880): Renglones cortos. (Ensayos literarios), Málaga, Tip. de El Mediodía.

- (I88I): Dos poesías. Con una carta de D. Gaspar Núñez de Arce, Málaga-Madrid, Tip. de El Mediodía-Bailly-Bailliere.

- (I883a): Noventa estrofas. Con una carta de Don Gaspar Núñez de Arce. Cuaderno primero, Madrid, Establecimiento Tipo-Litográfico, 1883. 
- (I883b): Cuadros de Andalucía. Cuaderno segundo, Madrid, Est. Tipo-Litográfico.

- (I883c): Don Ramiro. Poema, Madrid, Est. Tipo-Litográfico.

- (I885): Poema nacional. I Costumbres populares, Madrid, Est. Tip. de Ricardo Fe.

- (2016): Obras completas. Poesía I (1880-1890), Málaga, Universidad de Málaga. (Ed. de Elena Garcés.)

Ruiz De Almodóvar, Gabriel (1891): Salvador Rueda y sus obras, Madrid, Tip. de Manuel Ginés Hernández.

SÁnChez Andrés, Agustín (2003): "La élite política del Ministerio de Ultramar (1863-1898). Un estudio de sociología ministerial", Tzintzun. Revista de Estudios Históricos, 37, pp. 11-50.

Soria Andreu, Francisca (2002): "Los ateneos: su origen y función cultural y social", Ateneo de Castellón. Anuario 2001-2002, 11, pp. 7-14.

Tamayo, Juan Antonio (1943): "Salvador Rueda o el ritmo", Cuadernos de Literatura Contemporánea, 7, pp. 3-35.

VÁzquez Otero, Diego (1960): Salvador Rueda, Málaga, Gráficas Reunidas. 
